\title{
RELAÇÕES CRECHE-FAMÍLIA SEGUNDO EDUCADORAS DE CRECHES ${ }^{1}$
}

\section{RELATIONSHIPS BETWEEN DAY CARE CENTER AND FAMILY ACCORDING TO DAY CARE CENTER'S EDUCATORS}

\author{
Maria L. Ó. R. Veríssimo ${ }^{2}$ \\ Magda A. Rezende ${ }^{3}$ \\ Rosa M. G. S. Fonseca ${ }^{3}$
}

VERÍSSIMO, M. L.; REZENDE, M. A.; FONSECA, R. M. G. S. Relações creche-família segundo educadoras de creches. Rev. Bras. Cresc. Desenv. Hum., São Paulo, 2003.

\begin{abstract}
Resumo: Neste trabalho, apresentamos parte dos resultados de uma investigação cujo objetivo foi apreender e analisar as representações de educadoras de creches acerca do cuidado da criança, segundo o referencial da Teoria das Representações Sociais. Os dados foram coletados em três creches de uma universidade pública, no município de São Paulo, SP, durante uma oficina pedagógica. A análise dos conteúdos referentes à interação creche-família caracterizaram-na como uma relação difícil e delicada, pois as educadoras tinham expectativas idealizadas a respeito das mães e das famílias, bem como dificuldades para lidar com as manifestações de seus sentimentos, principalmente no que diz respeito a como conversar sobre tais assuntos. Esses fatores constituem- se em barreiras à interação, que precisam ser identificadas e trabalhadas para uma possível superação e construção de parcerias efetivas para o cuidado/educação infantil. Diante desses resultados, propomos que sejam incluídos, na formação das educadoras, conteúdos sobre habilidades e técnicas de comunicação terapêutica.
\end{abstract}

Palavras-chave: educação infantil; creches; cuidado da criança.

\section{INTRODUÇÃO}

No Brasil, as creches e pré-escolas, destinadas ao atendimento de crianças de 0 a 6 anos, integram a Educação Básica, com o ensino fundamental e o médio. Dos 21 milhões de crianças nessa faixa etária, a imensa maioria ainda não tem acesso a esse tipo de serviços: somente $8,3 \%$ das crianças menores de 4 anos estão matriculadas em creches, e $57 \%$ das de 4 a 6 anos em pré-escolas (UNICEF, 2001, p.37). Não obstante, o número das que freqüentam tais instituições é um grande universo (6,3 milhões segundo o UNICEF, 5,9 milhões segundo o

1 Baseado em capítulo da Tese de Doutorado: Veríssimo, MLÓR. O olhar de trabalhadoras de creches sobre o cuidado da criança. São Paulo, 2001. Escola de Enfermagem da USP. Orientadora: Rosa Maria Godoy Serpa da Fonseca.

2 Escola de Enfermagem da Universidade de São Paulo. Correspondência: Maria De La Ó. Ramallo Veríssimo. Av. Dr. Enéas de Carvalho Aguiar, 419. CEP 05403-000. São Paulo - SP. E-mail: mdlorver@usp.br

3 Escola de Enfermagem da Universidade de São Paulo. 
INEP - dados de 2001), tendo, portanto, o seu processo de desenvolvimento desenhado nesse contexto ao lado do ambiente familiar.

Considerando o peso de tais instituições no desenvolvimento infantil, sua tendência de uso crescente e as dificuldades encontradas na prática cotidiana, justifica-se conhecer como mães/famílias e trabalhadoras de creche se percebem e se relacionam.

HADDAD (1987) relatou uma experiência em pesquisa-ação, iniciada numa creche da prefeitura do município de São Paulo há quase 20 anos, época em que as creches ainda eram concebidas como locais de guarda e proteção da infância pobre, como substitutas maternas, e a educação para a primeira infância tinha como esteio os princípios da educação compensatória. Nesse cenário, a autora verificou que a disputa entre mães e pajens (denominação das trabalhadoras que cuidavam das crianças) decorria, em primeira instância, dessa representação de que a função da creche era substituir os cuidados maternos. As pajens viam as mães como não cumpridoras do papel que lhes competiria e desenvolviam sentimentos de rejeição a elas. Vale destacar que as próprias educadoras justificavam o afastamento materno pela lógica inexorável da necessidade econômica: em conseqüência das precárias condições de vida das famílias, as mães seriam obrigadas a trabalhar para garantir seu sustento. Ainda assim, o sentimento de rejeição desencadeava comportamentos de recriminação e cobranças. Por sua vez, as mães percebiam as recriminações que, somadas aos próprios sentimentos de culpa por deixarem os filhos aos cuidados de outras pessoas, repercutiam em reações também de recriminações e cobranças às pajens.

Em trabalho mais recente, VITÓRIA (1997) comparou as representações de educadoras sobre as mães e famílias de duas creches, sendo uma delas universitária e a outra filantrópica, de município do interior de São Paulo. Um dos principais resultados encontrados foi a semelhança das representações acerca da mãe como o principal elemento do desenvolvimento infantil e, portanto, que esta deve trabalhar pela educação do filho em casa, mas, geralmente, não o faz. A autora destaca que esse resultado não teve diferença entre as creches, a despeito das diferenças entre elas: a creche universitária dispõe de educadoras com formação mínima de ensino médio e atende, na maioria, famílias de classe média, enquanto a filantrópica tem metade de suas educadoras com ensino fundamental incompleto e atende famílias muito pobres e com precárias instrução e inserção no mercado de trabalho.

Percebe-se que o encontro creche-família para compartilhar um mesmo projeto de ação - o cuidado e educação da criança - não se dá sem percalços.

Visando contribuir para o debate acerca deste tema, este trabalho centrou-se nas percepções de trabalhadoras de creches sobre as suas relações com as famílias, tendo em vista as mudanças ocorridas na definição oficial da função das creches na Lei de Diretrizes e Bases da Educação Nacional, promulgada em 1996. Segundo esta, as creches passaram a compor a Educação Infantil, em conjunto com a préescola. Atualmente, a política nacional de creches, expressa em documentos como o Referencial Curricular Nacional para a Educação Infantil (BRASIL, 1998), define tais instituições como educativas, sem caráter escolar, cujas funções complementares e indissociáveis são educar e cuidar, o que não ocorria anteriormente a esta Lei.

\section{METODOLOGIA}

O estudo original objetivou apreender e analisar as representações sociais de trabalhadoras de creches acerca do cuidado da criança. Foi realizado em três creches de uma Universidade Pública, situadas no município de São Paulo, consideradas instituições de qualidade destacada no cenário nacional. A opção por esse locus de investigação teve a pretensão de, partindo de uma prática diferenciada, contribuir para o debate sobre princípios e diretrizes para os projetos de atendimento das instituições de educação infantil. A esse respeito, WILHEIM (1991, p.20) afirma: 
As creches nas universidades são excelentes experiências que reúnem teoria e prática, reunião essa muito necessária para o aprofundamento científico do atendimento, principalmente no que diz respeito aos aspectos educacionais. (...) são as creches de universidades que permitem inovações.

O referencial teórico-metodológico foi a Teoria das Representações Sociais, pois o cuidado da criança é um tema interpretado tanto pela ciência como pelo senso comum.

A população foi constituída por 16 trabalhadoras das creches, sendo 9 educadoras 13,4\% do total das trabalhadoras responsáveis pelas atividades diretas com às crianças - e 7 coordenadoras - todas as profissionais das equipes técnicas que estavam atuando na época, responsáveis pela coordenação e supervisão das atividades.

Para a coleta de dados com as educadoras, realizou-se uma oficina educativa, um tipo de técnica projetiva, grupal e associada à verbalização (CHIESA, 1993; FONSECA, 1996). As reuniões da oficina foram gravadas e transcritas na íntegra e os dados submetidos à análise de conteúdo, segundo a técnica de análise temática.

O projeto foi aprovado por Comitê de Ética e as trabalhadoras assinaram formulário de consentimento livre e esclarecido, após conhecimento do objetivo e finalidade do trabalho, forma de coleta dos dados e de apresentação do relatório e da garantia do anonimato das informações.

\section{RESULTADOS E DISCUSSÃO}

Apresenta-se aqui apenas os resultados referentes às educadoras, considerando serem elas o contraponto da mãe no cuidado-educação da criança que freqüenta creche.
A idade das educadoras variou de 23 a 42 anos, sendo a média 32 anos. Três concluíram o Ensino Médio, modalidade magistério, quatro finalizaram um curso superior (pedagogia, psicologia e sociologia) e duas tinham curso de pedagogia incompleto. O tempo de trabalho nas creches do estudo variou de 2 a 10 anos, sendo que duas tinham menos de 4 anos e as demais acima de 5 anos de vínculo. Seis educadoras tiveram experiência de trabalho anterior em outras creches e 3 em outras atividades. Três delas atuaram somente nas creches da universidade. Os aspectos relativos à interação trabalhadoras da creche e família da criança foram descritos na categoria $a$ criança e $a$ creche, a qual formou-se pelas subcategorias: Fatores envolvidos nas interações da equipe da creche com a família, e Medidas para favorecer a interação da creche com a família.

\section{FATORES NAS INTERAÇÕES DA EQUIPE DA CRECHE COM A FAMÍLIA}

Esta subcategoria inclui sentimentos, comportamentos e expectativas que modulam as interações creche-família. Foi possível, também, apreender alguns pontos de vista destas trabalhadoras na posição de mães/ usuárias, pois algumas fizeram referências às próprias experiências com os filhos na creche.

\section{Sentimentos que influenciam as interações creche-família}

As trabalhadoras das creches expressam que a relação com as famílias, na maior parte das vezes representada pela mãe, é fundamental e constante, mas que as interações nem sempre são fáceis. Nas palavras das educadoras:

Quanta dificuldade tem no relacionamento da família com a creche! 
Dentre os fatores de conflito está a "competição" a respeito de quem é melhor para assegurar o desenvolvimento da criança. Um exemplo corriqueiro é o ciúme da mãe em relação à educadora, quando a criança demonstra gostar muito desta:

Eu fico incomodada, porque você não sabe o que responder, quando a mãe fala: mas ele gosta tanto de você!. Porque ela não conta: que bom que ele gosta de você!!... Ela está mostrando: nossa, mas ele gosta mais de você do que de mim!.

As manifestações de sentimentos e conflitos familiares provocam desconforto nas educadoras porque, muitas vezes, elas não sabem como lidar com essas questões.

\begin{abstract}
A gente tenta entender a mãe, mas a gente tem dificuldade em como expressar prá ela esse é o processo mesmo, essa é a relação que ele primeiro está construindo, depois ele vai identificar a gente como a educadora, e a mãe é uma outra coisa.
\end{abstract}

Ainda, segundo elas, os pais sofrem com incidentes que ocorrem na creche, bem como com riscos potenciais da convivência com outras crianças no ambiente coletivo.

\section{É difícil prá esses pais viverem o co- letivo da creche, de ver que a crian- ça caiu, bateu, mordeu, é difícil prá eles agüentarem esse coletivo...}

Para as educadoras, os pais também sofrem e sentem-se inseguros quando têm que deixar a criança com uma educadora que não lhes é muito familiar, quando a criança chora para ficar na creche e ainda se houve experiências anteriores desagradáveis. As educadoras se sentem mal com as manifestações desses sentimentos, pois os consideram falta de confiança em seu trabalho.
O sentimento de culpa das mães é outro fator que pode dificultar as relações:

\begin{abstract}
A gente tem que estar controlada, tranqüila, para poder lidar com a mãe e com a criança. Tem mãe que fala: a mamãe vai te deixar aqui na creche, não briga com a mamãe, pedindo desculpa. Isso acontece, o sentimento de culpa da mãe [por] estar deixando lá, não poder ficar com ele.
\end{abstract}

Novamente, percebe-se que as educadoras não conseguem lidar com angústias e outras manifestações de dificuldades como, no caso, o sentimento de culpa dos pais. Justamente o fato de ficarem paralisadas diante de tais situações potencializa o risco de surgir um conflito entre mãe e educadora. Cabe apontar que as situações relatadas são corriqueiras, portanto, esperadas e "normais".

Além disto, elas sentem-se menosprezadas quando ouvem dizer que as educadoras que são mães sabem cuidar melhor de crianças. Percebem esta representação como uma desvalorização de seu trabalho, uma vez que desejam ser reconhecidas por sua competência profissional.

Assim, é um ponto de conflito das educadoras com os pais a visão de que o trabalho que elas realizam não corresponde à concepção de educadora ou professora.

\begin{abstract}
Os pais não têm clareza do nosso papel na educação infantil. Por mais que a gente faça, como professor, porque a maioria o é, nós não somos uma escola.
\end{abstract}

Entretanto, a definição do próprio papel profissional fica confusa não só como reflexo das percepções dos pais mas também em decorrência das suas, considerando que não sa- 
bem definir o cuidado em termos profissionais, a não ser enquanto um apêndice das atividades educativas (VERÍSSIMO \& FONSECA, 2003).

Mais um indicador de que os pais não as vêem como profissionais é a surpresa que eles manifestam ao saberem que muitas delas fizeram faculdade.

A gente comenta: eu fiz faculdade, os pais fazem uma cara de espanto. - Você tem faculdade? Parece que descobriram a América, realmente são pessoas que sabem, profissionais que têm nível superior, elas estudaram.

É provável que essas manifestações dos pais decorram de sua representação sobre $a$ pessoa que cuida: mulheres que não precisam formação e cujo trabalho tem pouco valor. EMILIANI e MOLINARI (1998, p.94) relatam que, nas pesquisas sobre creche, as características das educadoras mais apreciadas pelos pais deixam emergir uma representação de "moças” (ao que perguntamos: não poderiam ser moços?) dotadas de características naturais como paciência, doçura, amor pelas crianças e “atitudes maternais" em detrimento de uma preparação profissional, portanto, intencional e científica.

A representação de que mães têm mais competência como cuidadoras e educadoras é muito difundida em nossa realidade e comporta também a representação de que, na falta de cuidados maternos, há necessidade de cuidados do mesmo tipo. Tais representações sustentaram a visão tradicional da creche como substituta materna.

Além disto, a surpresa dos pais provoca uma interrogação: em que medida tais manifestações podem ser decorrentes de uma apresentação precária da equipe e do trabalho? Considerandose a possibilidade de uma tal associação, seria importante investigar esse aspecto futuramente.

\section{Comportamentos que influenciam as intera- ções creche-família}

Os comportamentos mais citados foram os considerados inadequados pelas trabalhadoras, tais como situações em que as mães/pais querem aproveitar a distração da criança e sair sem avisar ou quando eles chegam apressados e saem correndo, mal dando tempo para a criança se despedir. Elas recriminam essa maneira de agir pois sabem que não atende às necessidades da criança e pode gerar-lhe insegurança. Atribuem tais comportamentos ao desconhecimento dos pais sobre as necessidades infantis, e sentem que "o problema fica nas mãos da educadora”.

Foi citada também a dificuldade para colocar limites a alguns comportamentos da criança, bem como em separar-se ao deixá-la na creche. Essas situações foram atribuídas a sentimentos de culpa e incomodam as trabalhadoras que não sabem como agir diante delas.

Além disso, surgiu uma outra percepção, igualmente importante pelo seu significado intrínseco e pelas potenciais conseqüências que traz em seu bojo: a de que os pais têm deixado muita responsabilidade para a escola porque "não sabem o que compete a eles na educação da criança". As potencialidades desta percepção remetem-nos a uma necessidade de revisão da agenda de trabalho entre famílias e instituições de ensino, com enfoque especial na definição de papéis.

Passados quase 20 anos do início da pesquisa de HADDAD (1987), e tendo as creches do estudo condições absolutamente diversas em termos da capacitação profissional prévia das educadoras e educação continuada, ainda encontram- se alguns resultados semelhantes. Seriam tais resultados próprios da realidade brasileira? Na verdade, observamos que nossa experiência é similar à italiana descrita por BONOMI (1998) no que se refere às recriminações aos pais. Tal como seus pares italianos, as nossas se queixam de uma série de compor- 
tamentos e atitudes parentais que consideram inadequados em relação às crianças e desrespeitosos em relação a elas mesmas. É conveniente destacar que tais recriminações "apresentamse idênticas, salvo algumas exceções, em creches que possuem histórias e percursos diversos, sinal de uma dificuldade geral, somente em parte imputável a contingências particulares" (BONOMI, 1998, p.164, grifo nosso).

Para esse autor, é esperado que se ocupar da mesma criança, a partir de posições e contextos tão diferentes como a família e a creche, origine dificuldades e conflitos. O risco aqui implicado é que os conflitos tornem-se crônicos, bloqueando a relação, parecendo "impossível que de alguma parte surjam iniciativas ou sejam acionados procedimentos voltados a uma efetiva superação do conflito" (BONOMI, 1998, p.164).

Além dos comportamentos da família, há comportamentos das educadoras que também podem dificultar a interação, ainda que não seja assim percebido por elas.

\begin{abstract}
Tem um pai que não troca [a fralda da criança] de jeito nenhum. Ele tem consciência de estar agindo mal, mas como ele tem essa dificuldade, se justifica, a gente fala: tudo bem M., mas a gente deixa bem claro que está abrindo uma concessão porque aquele momento é dele e do filho.
\end{abstract}

Quando a educadora diz que faz uma concessão, entende-se que ela pensa estar fazendo um favor, algo excepcional. Ou seja, ela entende que o pólo da decisão pertence só a ela, e não ao pai também. Tendo-se por base tal premissa, a possibilidade de complementaridade creche-família é escassa, pois complementaridade implica necessariamente em assunção de papéis simétricos inclusive em potencialidade de decisão. Além disto, o tempo todo, há necessidade de ser flexível no cotidiano, o que não significa jogar por terra as rotinas, mas tão somente não reificá-las.

\section{Expectativas que influenciam a interação creche-família}

Ao reclamarem dos comportamentos "inadequados" dos pais, as educadoras estão manifestando, implicitamente, suas expectativas: que eles não atrapalhem mas sim ajudem a criança a permanecer na creche sem problemas, que ajam com segurança, que atuem como bons educadores. Ademais destas, esperam que a família esteja comprometida com o conteúdo que a creche quer ensinar, pois dizem: "se a família se compromete com o conteúdo, a criança aprende melhor”.

A gente necessita de compromisso da
família com o conteúdo que a creche
está querendo passar. Se tiver esse
comprometimento, o conteúdo que a
escola traz é absorvido pela criança
(...) porque ele é valorizado.

Diante de tais expectativas, percebemos uma visão idealizada sobre a família que, face à realidade, leva as educadoras a uma ambivalência de idéias e sentimentos. O discurso de que a família deveria ter o compromisso de viabilizar o trabalho educativo da creche traz em seu bojo a idéia de que este é o prioritário, desconsiderando que no âmbito intrafamiliar também acontecem experiências e relações igualmente importantes para a criança.

VITÓRIA (1997) também verificou ressentimentos das educadoras sobre a falta de envolvimento das famílias em relação aos filhos e sobre o trabalho da creche com eles. PIOTTO et al. (s/d) afirmam que os educadores “acabam adotando uma postura, muitas vezes inconsciente, de superioridade em relação aos pais”. Ora reclamam deles, dizendo que não participam e não continuam em casa os trabalhos iniciados por eles, ora desculpam-nos, dizendo que os pais "não têm condições". Para as autoras, embora essas posições sejam contrárias (acusação X pena), "refletem uma pos- 
tura de contraposição do educador, numa tentativa clara e desesperada de se diferenciar dos pais e valorizar seu papel”.

Assim, a expectativa da equipe acerca do cuidado que deveria ser oferecido à criança pela família também é um dos fatores que podem gerar divergências. Quando a realidade não corresponde, a família é vista como não capaz, não boa.

Se a relação entre a creche e a família se constrói com base em um estereótipo, significa que não se está considerando a diversidade de formações culturais e as conseqüentes diferenças de valores e práticas. Mais do que isso, ao rejeitar a cultura da família, postula-se que a única forma correta de agir para com a criança é a da creche. Mas é oportuno ressaltar que do lado da creche e das trabalhadoras aí inseridas também há uma diversidade que, possivelmente, não tem sido considerada. Consoante afirma BONOMI (1998, p.168), não existe "a família”, como também não existe "a creche”. No entanto, as trabalhadoras colocam-se como se houvesse uniformidade absoluta nas experiências ocorridas na creche.

Os discursos a seguir evidenciam a idéia de que o profissional sabe o que é o correto e pode oferecer coisas para os pais, visando que melhorem sua atuação com a criança e sua relação com a creche.

A gente pede muito que tragam palestrantes para falar com os pais. Por mais que a gente fale, e eu vejo isso em todos os pais, o profissional tem essa arma de estar falando, tem um outro peso, e isso é importante.

Para as educadoras, falta algo aos pais e, portanto, há a necessidade de intervençõe educativas, inclusive com ajuda de outros profissionais que ostentam a condição de "especialistas" e cuja fala tem o peso da autoridade. De maneira semelhante, percebem que elas próprias também podem contribuir para a instrução dos pais.
Outro dia uma mãe estava questionando a coisa do falar "o fulano fala errado e a mãe em vez corrigir..." [a educadora respondeu] "a gente não trabalha mesmo dessa forma. Ao invés de recriminar, a gente diz a palavra correta e a criança já vai perceber. Por exemplo, a aga, você quer água? Então ele já vai assimilando isso". Eu pensei o quanto a gente está instruindo esses pais. Não precisa do autoritarismo o tempo todo.

É meritória a preocupação da educadora em compartilhar com os pais os conhecimentos e práticas da creche. No entanto, não houve menção ao que pais e mães poderiam ter ensinado às educadoras, o que é intrigante. Na verdade, o saber dos pais pode ter outros fundamentos, diferentes do saber da creche. E, quando isso não é considerado, está se incutindo um valor menor à cultura da família.

Por sua vez, a família tem dificuldade para colocar seu saber por vários motivos, sendo uma das razões a apontada por CIPOLLONE (1998, p.124): “o saber familiar é dificilmente comunicável,

mesmo no seu interior, é um saber

nascido na prática, não sistemático, emotivamente conotado". O assunto merece um maior aprofundamento.

Ademais, tal como se dá com qualquer pessoa, para que os pais assimilem um novo conceito, uma nova visão, é necessário que essa nova visão faça sentido para eles. Se não houver uma reflexão conjunta sobre o que fundamenta uma determinada ação para com a criança, é possível que eles continuem acreditando que o seu modo de agir é o melhor.

\section{A experiência das educadoras ao ter um filho na creche}

Quando as educadoras estão no papel de mães, à semelhança das outras mães, tam- 
bém se sentem ansiosas, têm dúvidas e receios sobre o atendimento dos filhos.

\begin{abstract}
As minhas filhas estão na creche 1. No começo, eu fiquei meio preocupada porque era outro ambiente, outras pessoas. Quando ela começou a ir, eu achei que fosse desmontar, fiquei muito angustiada, pensando: será que elas vão colocar travessei ro atrás da cabecinha da menina, será que vão lavar o brinquedo que caiu?
\end{abstract}

É curioso verificar que elas reconhecem, na própria experiência, a necessidade de certificarem- se de que a criança está bem cuidada e feliz na creche, como reconhecem essa mesma necessidade nas outras mães, mas não sabem como lidar com os comportamentos associados a ela. Isso é visível quando cogitam que as mães podem ter dúvidas sobre o que acontece realmente na creche.

Eu tenho as minhas crianças na creche e conheço o trabalho das meninas $e$, às vezes, também tenho dificuldade de passar as minhas filhas, porque a gente não sabe como está sendo lá dentro. Eu penso: e o outro que está lá no HU [Hospital Univer sitário], ou não sei aonde?

Assim, é surpreendente que as educadoras sintam-se tão desconfortáveis com as manifestações de insegurança das mães, sendo que elas próprias sentem-se inseguras em relação ao atendimento que as colegas dispensam a seus filhos. Uma forma que elas encontram para lidar com essa insegurança, é procurar garantir que o filho fique na mesma creche onde trabalham.

Eu também não quis que [os filhos] fossem [para outra creche], porque eu pensei: é longe, se tiver alguma coisa até eu sair daqui, chegar lá...
Reiteradamente, surgem as ambivalências entre os papéis de mãe e trabalhadora: como trabalhadora conhece o serviço e reconhece sua qualidade mas, como mãe, quer o filho sob a sua vigilância. Ao mesmo tempo, quando a mãe usuária se comporta tal como ela, entende isso como falta de confiança no serviço, ou melhor, nas educadoras.

Finalmente, é interessante assinalar que, embora não desejem ser consideradas melhores ou piores educadoras pelo fato de serem ou não mães, no discurso a seguir, aparece a premissa de que o fato de ser mãe favorece que a educadora compreenda melhor as outras mães.

Falando como mãe, é tão mais fácil entregar o seu filho quando você tem essa relação boa, essa cumplicidade. Como mãe você consegue entender um pouco aquela mãe e aquela criança que está entrando.

A seguir, pontua-se as intervenções realizadas pelas educadoras para favorecer a interação creche-família.

\section{MEDIDAS PARA FAVORECER A INTERAÇÃO CRECHE-FAMÍLIA}

As ações que favorecem a interação creche-família, relatadas pelas educadoras foram: ter respeito mútuo, desenvolver confiança e ajudar os pais em suas inseguranças.

\section{Ter respeito mútuo}

O respeito mútuo é necessário para que a creche e a família possam conviver no atendimento da criança:

A gente faz um pedaço, a outra parte é da mãe, é da família, e não tem como $a$ gente estar se intrometendo, entrar 
nesse campo. Como eles também têm que respeitar nosso trabalho.

A idéia de respeito mútuo aparece no sentido da não interferência, considerando principalmente que as diferentes realidades de vida das famílias constituem-se em situações que as educadoras gostariam que fossem diferentes, mas sobre as quais não podem intervir. Evidencia-se que o foco de preocupação é a criança.

E a criança sofre as influências de casa, mesmo não sendo sempre tão positivo, às vezes traz conflitos que, na verdade, não estão sob nosso alcance, nem de intervir, nem de julgar, mas de facilitar para a criança sentir-se bem, a gente tenta ajudar (...)

\section{Desenvolver confiança}

Há preocupação explícita de construir um relacionamento de confiança, fornecendo conhecimentos antecipados das intervenções que se realizarão, procurando conhecer as peculiaridades de cada criança e família.

É bem importante prá mãe confiar
mesmo na educadora. Se você não
conseguir essa cumplicidade com a
mãe, o trabalho vai ficar meio trun-
cado, porque, automaticamente, a
criança também vem contagiada com
aquele sentimento.

Assim, não basta preocupar-se com as mães no período de adaptação, pois, segundo as educadoras, um incidente pode colocar em questão essa confiança.

Mas a gente tem que reconstruir todo dia aquele vínculo de confiança porque é só a criança aparecer com uma mordida... Desmorona.
É, no mínimo, curioso constatar esse grau de auto-exigência. Será que a confiança da família desmorona mesmo quando algo como uma mordida acontece? Esse é mais um dos pontos a ser trabalhado nos encontros entre creche e família pois, por melhor que seja a qualidade do serviço é impossível garantir que todas as crianças nunca sejam mordidas, por exemplo.

Para evitar a perda da confiança, foram estruturadas várias atividades visando favorecer as relações com as famílias, que as educadoras consideram valiosas.

Na instituição, parece que já tem a preocupação de dar tranqüilidade para a família e criar esse elo família-creche, creche-família. Tem projetos que a família pode vir passar um dia com a criança, ou da criança levar prá casa um objeto da creche, não só trazer. A gente faz oficinas, a família pode ficar com a criança aquele dia, irmão, primo, tio, quer dizer, é um lugar gostoso.

\section{Ajudar os pais em suas inseguranças}

Verificou-se que as equipes têm uma grande preocupação com o período de adaptação e buscam soluções criativas, antecipando respostas às dúvidas e angústias, particularmente no que se refere ao impacto da inserção na creche para a criança. A medida mais comentada para transmitir segurança durante a adaptação foi confirmar que os pais são chamados caso a criança não fique bem.

\section{Se a mãe está muito ansiosa, ela pode ligar ou avisar e dar uma passadinha na hora do almoço e ver que está dormindo, vê que está brincando...}

Parece que o mal-estar dos pais é ligado somente ao sofrimento da criança. Não se cogita sobre um mal-estar ligado aos próprios pais e seus sentimentos de perda por deixarem a 
criança na creche. Apesar de saberem que isto existe, no momento da ação aparece somente o alívio ao sofrimento da criança. MANTOVANI e TERZI (1998) explicam que os pais podem apresentar comportamentos de crise bem parecidos com os que estamos acostumados a estudar na criança - apego ansioso ou recusa incoerente - quando eles não conseguem acompanhar as etapas da mudança da criança e, por isso, sentem-se dispensáveis e não conseguem exercer seu papel. Assim como para com a criança, é preciso ser empático, isto é, reconhecer as necessidades da família, segundo o significado que tem, para eles, essa experiência.

Mesmo assim, as educadoras manifestam que muitos pais têm reconhecido sua atenção e disponibilidade, pois alguns adquirem confiança a ponto de compartilhar questões íntimas e conflitos familiares.

\section{CONSIDERAÇÕES ACERCA DOS RESULTADOS}

Os principais pontos em comum nos discursos das educadoras foram a representação da interação creche-família como difícil e delicada, e um conteúdo ideologizado em relação ao papel da mãe e da família. Em suas verbalizações, percebe-se o desejo da inexistência de conflitos. As educadoras manifestam-se acolhedoras às angústias e dificuldades familiares, mas demonstram sua própria angústia diante delas.

Uma explicação para as representações das educadoras pode ser encontrada na história. No seio das famílias ocidentais, nos últimos séculos, particularmente as mães têm tido a responsabilidade de cuidar e educar os filhos, de forma a torná-los pessoas capazes de viver em sociedade. A mulher é vista como naturalmente dotada para a maternidade e criação dos filhos, ainda que isto já tenha sido amplamente contestado em estudos sociológicos, e a sociedade,em geral, não assume compromisso para com o cuidado das crianças nem para com as mães, no sentido de apoiá-las.

Todas as queixas a respeito dos comportamentos que dificultam a interação, centralizados na pessoa da mãe, mostram a expectativa de uma mãe ideal, a mãe boa, que cuida da criança (como a creche cuida), que supera suas angústias e culpas, que respeita as regras da creche, que ensina o conteúdo que a creche quer ensinar. Diante da mãe real, que faz chantagem com a criança, que quer sair escondida, que chora durante a adaptação, as educadoras podem desestabilizar-se, tendo que lançar mão de regras e limites, muitas vezes solicitando intervenção da direção, o que denota que a mãe real foi percebida como desviante e ameaçadora.

A cobrança, exigência, expectativa em relação às mães caracteriza o ideal de maternidade que é a perfeição no exercício desse papel. Quando as mães não conseguem ser "perfeitas", não só é reconhecido que há um sentimento de culpa como também é esperado que ele esteja presente, pois, a boa mãe sente culpa. Esse sentimento é, de certa forma, vivido pelas próprias educadoras, quando entendem que "qualquer problema que ocorra com a criança na creche faz desmoronar a confiança dos pais". Elas projetam nos pais seus próprios sentimentos de angústia por não poderem controlar todas as situações e evitar todos os riscos para as crianças. Demonstram não aceitar possíveis falhas, um sentimento de que têm que dar conta de tudo e, quando não conseguem, projetam no outro essa cobrança, a recriminação.

A ambivalência vivenciada no papel de mãe também precisa ser olhada. A oportunidade de estar no papel da mãe, nessa relação entre a creche e a família, poderia permitir à educadora a possibilidade de compreender melhor a situação e as dificuldades das mães usuárias da creche e pensar em como atendê-las. Mas, vê-se que esse processo não é automático, talvez porque as educadoras também não tenham 
vivido experiências nas quais foram sistematicamente atendidas em suas angústias e, portanto, não tenham como aproveitar o aprendizado da própria vivência.

Conforme discutido anteriormente, os conflitos nas relações entre a creche e a família não são privilégio da realidade brasileira. Segundo BONOMI (1998), as educadoras italianas manifestam dificuldades na administração de relacionamentos complexos como os de educador-criança-mãe-pai e conseguem explicitar melhor suas competências didático-educacionais. Isto é explicado pelo autor como decorrência de uma imagem consciente do próprio profissionalismo mais estreitamente vinculada a essas competências. De maneira semelhante, as trabalhadoras deste estudo também explicitaram e justificaram com maior propriedade as ações educativas que realizam com as crianças (VERÍSSIMO \& FONSECA, 2003).

Assim, evidencia-se a força das representações socialmente construídas e a necessidade de maior investimento na formação continuada em serviço visando assuntos relacionados à maternidade e função materna e complementaridade creche-família. A formação continuada, tal como a formação prévia, tem um papel angular na re-significação das representações ligadas ao trabalho de educação infantil coletiva.

Entendemos que pais que utilizam creche precisam dividir a responsabilidade educativa e a criação da criança sem renunciar a seu papel, fato que desencadeia reações fortes, muitas vezes ambivalentes e difíceis de serem decodificadas:

Existem medos, às vezes desconhecidos ou não explicitados, que deveriam ser detectados e entendidos para que estratégias adequadas sejam implementadas. Por exemplo, $o$ medo que sentimos das opiniões dos outros às vezes é um sentimento forte, que marca as etapas iniciais do relacionamento, quando algumas coisas não são ditas para agradar o outro. Outro sentimento comum é o medo de perder poder ou status. Os pais estão autorizados, por seu status natural, a decidir por suas crianças, mas devem sempre mostrar que são bons pais. Os trabalhadores da creche podem sentir que sua posição como pessoas habilitadas e competentes está ameaçada: a capacidade e a qualidade de "especialistas" que os pais enxergam neles pode então ser questionada, se os educadores não puderem identificar ou responder às demandas dos pais ou necessidades específicas das crianças."

(GHEDINI, 1994, p. 206-7)

Se, conforme preconiza o Referencial Curricular Nacional para a Educação Infantil (BRASIL, 1998), creche e família têm papéis complementares na educação e cuidado da criança, é preciso consolidar uma interação saudável, permeada por troca, tolerância, confiança. Considerando que o cuidado da criança compartilhado por vários adultos é uma dinâmica relacional complexa, mesmo entre membros da própria família, fica patente que não há como eliminar o surgimento de conflitos. Assim, a interação saudável demanda o reconhecimento desses conflitos e sua superação.

Para isso, o papel profissional das trabalhadoras também precisa contemplar o saber referente aos aspectos envolvidos na dinâmica das interações humanas, considerando que tal saber não é só cognitivo mas também emocional, reflexivo. Para o estabelecimento de estratégias que permitam maior segurança a todos os envolvidos na relação é imprescindível que seja pensado sobre as interações e que se compreenda as manifestações de cada pessoa, identificando-se os sentimentos e valores imbricados, isto é, o exercício da compreensão empática. 
Embora não tenhamos descrito neste texto os discursos das coordenadoras, cabe ressaltar que foram destacados muitos exemplos de como elas procuram trabalhar tais questões na educação continuada das educadoras e que, inclusive, também procuram refletir com as educadoras sobre os aspectos emocionais envolvidos. Mas, consoante os resultados, evidenciouse como é difícil esse caminho. É perceptível que as maiores dificuldades surgem porque há muita carga afetiva envolvida nas relações, o que não se resolve trabalhando apenas com informações e conhecimentos.

Com base nisto, entendemos que também seria apropriado incluir o desenvolvimento de conhecimentos e habilidades de comunicação terapêutica na formação das educadoras. Destacamos a comunicação terapêutica pois esta permite ao profissional que a utiliza estabelecer relações interpessoais significativas e construtivas (REZENDE et al., 2002), mediante as quais estabelece-se confiança recíproca e podese atuar no sentido de lidar efetivamente com os conflitos. A base para a comunicação tera- pêutica, que é a compreensão de si mesmo e do outro, é um passo fundamental para a compreensão de que os conflitos são inevitáveis, pois surgirão sempre que houver idéias e práticas diferentes.

É preciso estar ciente de que a tecnologia das relações é uma das mais complexas, pois abrange não só conhecimentos, habilidades e comportamentos, como também atitudes. $\mathrm{Na}$ comunicação terapêutica, atitude comunicativa é a disponibilidade interna de se envolver na interação pessoa a pessoa, e o compromisso de utilizar a comunicação como instrumento de ajuda (CHIESA \& VERÍSSIMO, 2001).

Nessa reconstrução das interações, criamse condições para que as pessoas que cuidam (familiares e trabalhadoras das creches) redesenhem seus papéis e descubram novos contornos em si mesmas. Por exemplo, torne-se menos conflitante para os pais a idéia que outras pessoas além deles são significativas para o desenvolvimento da criança e, para as educadoras, o cuidado das crianças e dos pais seja visto como função intrínseca a seu papel profissional.

\begin{abstract}
This article presents part of the results from an investigation aiming to understand and analyze representations of those who work in day care centers concerning child care according to theory of social representations. Data were collected at three day care centers of a public university in the city of São Paulo. The population consisted of nine educators - workers in charge of the direct activities with children -, who answered a questionnaire with questions related to personal features and on their association with infantile education. The educators had participated in a pedagogical workshop, organized in four group meetings, and their speech was analyzed according to the thematic analysis technique. The category day care center and family, approaching aspects regarding the interaction between workers and family, consisted of two sub-categories: factors involved in the interaction between the day care center staff and the family, including feelings, expectations, perceptions and parents' and staff's behavior which modulate these interactions and measures to favor interactions between day care center and family, such as: mutual respect, developing confidence and helping parents in their insecurity. The analysis of the content regarding the interaction day carecenter/family characterizes it as a difficult and fragile relationship. It was observed that workers have an ideal view of mothers and families; they also have difficulties in dealing with manifestations of feelings, mainly regarding how to talk about them. These factors are barriers to the interaction, and they need to be identified and dealt with so that they can be overcome and effective partnerships for the infantile care/education can be built. Contents about abilities and therapeutic communication techniques are proposed to be included in the educator's education.
\end{abstract}

Key-words: child rearing; child day care centers; child care. 


\section{REFERÊNCIAS BIBLIOGRÁFICAS}

BONOMI, A. O relacionamento entre educadores e pais. In: BONDIOLI, A.; MANTOVANI, S. Manual de educação infantil: de 0 a 3 anos uma abordagem reflexiva. Porto Alegre: Ed. Artes Médicas, 1998. p.161-172.

BRASIL. Ministério da Educação e do Desporto. Secretaria de Educação Fundamental. Referencial curricular nacional para a educação infantil. Brasília, 1998.

CHIESA, A.M. O uso de estratégias participativas para o conhecimento das representações sociais de mulheres da região de Pirituba / Perus com resultado classe III de Papanicolau. São Paulo, 1993. [Dissertação de Mestrado - Faculdade de Saúde Pública da USP].

CHIESA, A.M.; VERÍSSIMO, M.L.ÓR. A educação em saúde na prática do PSF. In: Ministério da Saúde. Instituto para o Desenvolvimento da Saúde - IDS. Programa de Saúde da Família. Manual de Enfermagem. Brasília: MS / IDS / USP / Fundação Telefônica; 2001. p.34-42.

CIPOLLONE, L. A atualização permanente nas creches. In: BONDIOLI, A.; MANTOVANI, S. Manual de educação infantil: de 0 a 3 anos uma abordagem reflexiva. Porto Alegre: Ed. Artes Médicas, 1998. p.121-139.

EMILIANI, F.; MOLINARI, L. Os comportamentos parentais em relação à criança e à instituição. In:

BONDIOLI, A.; MANTOVANI, S. Manual de educação infantil: de 0 a 3 anos - uma abordagem reflexiva. Porto Alegre: Ed. Artes Médicas, 1998. p.88-95.

FONSECA, R.M.G.S. Mulheres e enfermagem: uma construção generificada do saber. São Paulo, 1996. [Tese de Livre-Docência - Escola de Enfermagem da USP].

GHEDINI, P.O. Entre a experiência e os novos projetos: a situação da creche na Itália. In: $\begin{array}{llllllllll}\mathrm{R} & \mathrm{O} & \mathrm{S} & \mathrm{E} & \mathrm{M} & \mathrm{B} & \mathrm{E} & \mathrm{R} & \mathrm{G}\end{array}$, F.; CAMPOS, M.M. (Orgs.). Creches e préescolas o hemisfério norte. São Paulo: Ed. Cortez / Fundação Carlos Chagas, 1994. p.189210.

HADDAD, L. A relação creche-família: relato de uma experiência. Cadernos de Pesquisa, (60):70-78, 1987.

INEP. A educação infantil no Brasil: 1994-2001. Disponível em: http://www.inep.gov.br/censo/ outros levantamentos/infantil/educação_infantil_ brasil.htm.11 de abril de 2002.

MANTOVANI, S.; TERZI, N. A inserção. In: BONDIOLI, A.; MANTOVANI, S. Manual de educação infantil: de 0 a 3 anos - uma abordagem reflexiva. Porto Alegre: Ed. Artes Médicas, 1998. p.173-184.

MELLO A.M. Um diálogo com os diretores de creches e pré-escolas. In: ROSSETTI-FERREIRA M.A.;

MELLO, A.M.; VITÓRIA, T.; GOSUEN, A.; CHAGURI, A.C. (Orgs.). Os fazeres na Educação Infantil. São Paulo: Ed. Cortez, 1998.

MELLO, A.M. História da Carochinha: uma experiência para educação de crianças abaixo de 3 anos em creche. Ribeirão Preto, 1999. [Dissertação de

Mestrado - Faculdade de Filosofia, Letras e Ciências Humanas da USP].

PIOTTO, D.C.; ROSSETTI-FERREIRA, M.C.; CHAGURI, A.C.; MELLO, A.M.; SILVA, A.P.; ELTINK,C.; YAZZLE C.H.; CARNIEL, I.C.; DE SORDI, G.; BALDIN, L.S.A.; FREDERICK, M.I.B.; MORAIS, R; BESANI, V. Promoção da qualidade e avaliação na educação infantil: contribuições da experiência com um instrumento australiano para a discussão brasileira. Ribeirão Preto (SP); s/d./Mimeografado.

REZENDE, M.A.; SIGAUD, C.H.S.; VERÍSSIMO, M.L.ÓR.; CHIESA, A.M.; BERTOLOZZI, M.R. $\mathrm{O}$ processo de comunicação na promoção do aleitamento materno. Rev. Latino-Am. Enferm., 10(2): 234-238, 2002.

UNICEF. Situação da infância brasileira 2001. Desenvolvimento infantil - os primeiros seis anos de vida. Brasília, Fundo das Nações Unidas para a Infância, 2001.

VERÍSSIMO, M.L.ÓR.; FONSECA, R.M.G.S. O cuidado da criança segundo trabalhadoras de creches. Rev. Latino-Am. Enferm. 2003, 11(1):28-35.

VITÓRIA, T. Representações de educadoras sobre as mães e famílias das crianças da creche. Ribeirão Preto, 1997. [Dissertação de Mestrado Faculdade de Medicina de Ribeirão Preto da USP].

WILHEIM, A.M. (Coord.). Questão social, políticas sociais no Brasil, avaliação e propostas para os anos 90: creche e educação básica. São Paulo: Fundap, 1991.

Recebido em 28/02/2003

Modificado em 20/03/2003 Aprovado em 30/03/2003 